\title{
OPTIMASI JARINGAN MICROWAVE SITE CIPETIR-CIBADAK DENGAN MENGGUNAKAN SPACE DIVERSITY
}

\author{
Zein Hanni Pradana ${ }^{1}$, Khoirun Ni'amah ${ }^{2}$, Solichah Larasati ${ }^{3}$
}

\author{
${ }^{123}$ Institut Teknologi Telkom Purwokerto \\ Jl. D.I Panjaitan no. 128 Purwokerto \\ Izeindana@ittelkom-pwt.ac.id, ${ }^{2}$ irun@ittelkom-pwt.ac.id, ${ }^{3}$ laras@ittelkom-pwt.ac.id
}

\begin{abstract}
Abstrak- Penelitian ini melakukan optimasi pada jaringan microwave site Cipetir-Cibadak dengan menggunakan space diversity dengan frekuensi kerja $32 \mathrm{GHz}$. Kondisi wilayah site Cipetir-Cibadak merupakan daerah perbukitan dengan jarak 11,42 $\mathrm{Km}$, sehingga diperlukan penambahan antena diversity. Optimasi jaringan microwave ini dilakukan menggunakan software Pathloss 5.0 untuk melihat perbandingan sebelum dan sesudah menggunakan antena diversity. Parameter yang digunakan pada performansi optimasi jaringan microwave ini adalah availability yang diperoleh berdasarkan simulasi menggunakan vigent barnet dan ITU-R. Nilai availability yang diperoleh sebelum optimasi berdasarkan vigent barnet $99,86112 \%$ dan ITU $99,87924 \%$, setelah pemasangan antena diversity pada jarak $100 \lambda, 125 \lambda, 150 \lambda, 175 \lambda$ dan $200 \lambda$ dan pada jarak $200 \lambda$ nilai availability meningkat berdasarkan vigent barnet $99,91027 \%$ dan ITUR 99,9118\%. Penggunaan teknik space diversity ini dapat meningkatkan kehandalan sistem.
\end{abstract}

Kata Kunci-Microwave, Optimasi, Availibility, Space Diversity.

Abstract- This research performed an optimization on the Cipetir-Cibadak site microwave network by using space diversity and frequency of $32 \mathrm{GHz}$. The condition of the Cipetir-Cibadak site area is a hilly area with a distance of $11.42 \mathrm{Km}$, so it is necessary to add a diversity antenna. This microwave network optimization using Pathloss 5.0 simulation software to show the comparison before and after using diversity antenna. The parameter used in this microwave network optimization performance is the availability obtained based on the simulation using the vigent barnet and ITU-R. The availability value obtained before optimization based on the vigent barnet $99.86112 \%$ and ITU $99.87924 \%$, after installing the diversity antenna at a distance of $100 \lambda, 125 \lambda, 150 \lambda, 175 \lambda$ and $200 \lambda$, at a distance of $200 \lambda$ the availability value increases, on the vigent barnet $99.91027 \%$ and ITU-R $99.9118 \%$. The use of space diversity techniques has succeeded in increasing system reliability.

Keywords—Microwave, Optimization, Availibility, Space Diversity.

\section{PENDAHULUAN}

Beberapa teknologi telekomunikasi yang sudah diterapkan di Indonesia seperti komunikasi seluler, komunikasi satelit dan komunikasi menggunakan media kabel fiber optic. Media komunikasi untuk pertukaran data antara pengirim dan penerima pada teknologi telekomunikasi seluler dan satelit menggunakan media udara/gelombang mikro (microwave) [1]. Teknologi wireless saat ini sangat banyak digunakan oleh masyarakat karena kemudahannya dalam penggunaan dan perangkat komunikasi yang bersifat mobile sehingga efisien untuk dibawa kemana-mana.

Komunikasi antar Base Transceiver Station (BTS) ataupun Base System Control (BSC) menggunakan media gelombang mikro, dimana komunikasi gelombang mikro ini rentan terhadap penghalang berupa pohon, gedung bertingkat dan daerah perbukitan serta terhadap perubahan cuaca [2]. Pada komunikasi gelombang mikro membutuhkan ruang bebas tanpa penghalang, dimana antara antena pengirim dan antena penerima tidak ada penghalang yang menghalangi lintasan perambatan gelombang mikro atau disebut dengan Line of Sight (LOS) [3].

Negara Indonesia merupakan negara yang banyak terdapat gunung maupun bukit yang menyebabkan komunikasi tidak LOS sehingga menyebabkan komunikasi yang dikirim tidak sepenuhnya sampai ke penerima. Gangguan yang disebabkan karena adanya lintasan ganda (multipath) akibat dari pantulan pada gunung dan bukit disebut dengan multipath fading [4]. Multipath fading ini juga menyebabkan masalah pada sisi pengguna karena jaringannya menjadi tidak stabil [3].

Parameter untuk mengukur performansi pada jaringan microwave adalah availibility atau disebut juga dengan kehandalan sistem. Secara ideal nilai availibility harus $100 \%$, namun hal tersebut tidak mungkin terpenuhi karena terdapat beberapa faktor 
yang menyebabkan loss. Terlalu besar nilai loss mengakibatkan penurunan nilai availibility dan peningkatan nilai unavailibility. Unavailibility merupakan ketidakhandalan sistem, dimana semakin besar nilai unavailibility maka kualitas layanan yang diberikan sistem akan berkurang [5].

Diversity merupakan suatu cara yang digunakan untuk mengoptimalkan jaringan microwave dengan menerapkan operasi sistem yang dilakukan dua atau lebih antena pada sistem secara bersamaan untuk meningkatkan kualitas sinyal yang diterima [6]. Terdapat tiga teknik diversity yaitu space, frekuensi dan hybrid diversity.

Penelitian ini melakukan optimasi dengan menggunakan teknik space diversity link jaringan komunikasi microwave pada site Cibadak-Cipetir dengan frekuensi kerja $32 \mathrm{GHz}$ dan jarak 11,42 Km. Kondisi pada daerah site Cibadak-Cipetir merupakan perbukitan sehingga cocok diterapkan teknik space diversity. Penerima pada radio gelombang mikro menerima sinyal dari dua antena yang terpisah secara vertikal dalam jarak 100 $\lambda, 125 \lambda, 150 \lambda, 175 \lambda$ dan $200 \lambda$. Setelah sinyal diterima oleh masing-masing antena kemudian secara simultan akan dihubungkan ke diversity combiner untuk menggabungkan sinyal yang diterima oleh antena penerima.

\section{METODE PENELITIAN}

Penelitian ini melakukan optimasi jaringan microwave pada site Cipetir-Cibadak dengan kontur bumi perbukitan, sehingga sinyal yang sampai ke penerima tidak bebas pandang maka perlu dilakukan optimasi. Optimasi yang dilakukan ialah menambahkan teknik space diversity disisi pengirim dan penerima. Analisis dalam penelitian ini berdasarkan studi kasus di sebuah perusahaan swasta Indonesia yang bergerak di bidang telekomunikasi. Data parameter input pada penelitian ini ditunjukkan pada Tabel I.

TABEL I

DATA PARAMETER INPUT PENELITIAN

\begin{tabular}{|c|c|c|}
\hline Parameter & Site Cibadak & Site Cipetir \\
\hline Frekuensi & \multicolumn{2}{|c|}{$32 \mathrm{GHz}$} \\
\hline Jarak & \multicolumn{2}{|c|}{$11,42 \mathrm{Km}$} \\
\hline Space Diversity & \multicolumn{2}{|c|}{$100 \lambda, 125 \lambda, 150 \lambda, 175 \lambda, 200 \lambda$} \\
\hline $\begin{array}{l}\text { Metode } \\
\text { Simulasi }\end{array}$ & \multicolumn{2}{|c|}{ Vigent Barnet dan ITU-R } \\
\hline
\end{tabular}

\section{A. Alur Penelitian}

Perancangan jaringan microwave diawali dengan penentuan lokasi site berdasarkan data yang diperoleh dari perusahaan swasta telekomunikasi di Indonesia. Langkah pertama melakukan pengumpulan data, dimana data tersebut diperoleh berdasarkan data realistik seperti garis lintang, garis bujur, jenis radio akses, antenna dan data radio lainnya sebagai parameter masukan dalam mendesain di software Pathloss dengan menggunakan teknik space diversity dan menggunakan dua metode simulasi yaitu vigannt barent dan ITU-R. Hasil simulasi kemudian dibandingkan dengan ketentuan standart ITU-T-G.821 dilihat dari parameter availability. Diagram alur penelitian ini ditunjukkan pada Gbr 1.

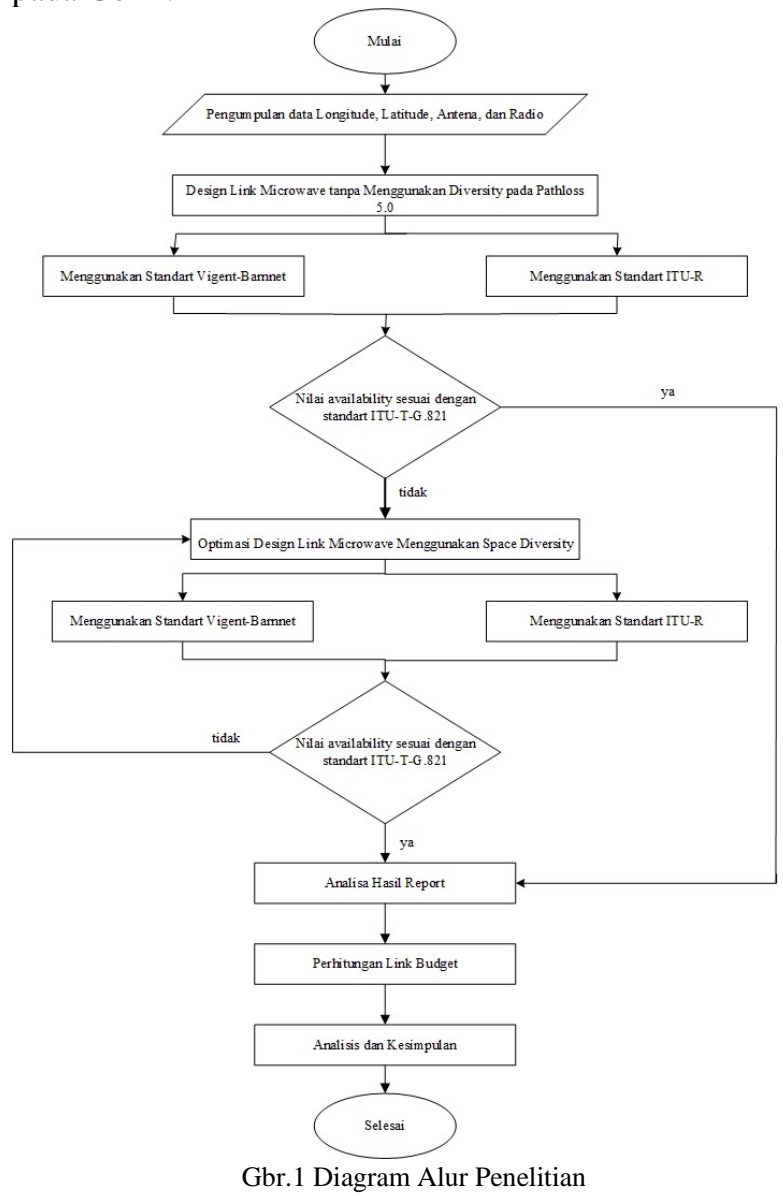

\section{B. Data Lokasi Site}

Lokasi site yang akan dilakukan optimasi pada pada penelitian ini adalah Cibadak dan Cipetir. Diperlukan data lokasi site seperti koordinat dan elevasi dari masing-masing site untuk membuat link jaringan microwave point to point. Dengan menggunakan data lokasi tersebut dapat melihat kondisi wilayah jaringan microwave yang dirancang. Berikut data lokasi site ditunjukkan pada Tabel II.

TABEL III

DATA KOORDINAT SITE

\begin{tabular}{|l|c|c|}
\hline Parameter & Site Cibadak & Site Cipetir \\
\hline Latitude & $065340.00 \mathrm{~S}$ & $065202.38 \mathrm{~S}$ \\
\hline Longitude & $1064706.38 \mathrm{E}$ & $1064107.58 \mathrm{E}$ \\
\hline Elevasi & $388,2 \mathrm{~m}$ & $664,4 \mathrm{~m}$ \\
\hline
\end{tabular}

Daerah pada site Cibadak dan Cipetir ini merupakan daerah perbukitan sehingga cukup menimbulkan banyak multipath yang dapat mengurangi nilai availability. Untuk dapat meningkatkan nilai availability diantara kedua site ini diperlukan optimasi dengan menambahkan teknik space diversity. 

budget terutama untuk availability pada sistem yaitu Vigant-Barent merupakan persamaan perhitungan yang digunakan untuk menghitung nilai availability sistem dari persamaan fading margin dengan memasukkan faktor jarak lintasan dan frekuensi [7]. Beberapa faktor yang mempengaruhi komunikasi gelombang radio pada perhitungan nilai link budget yaitu:

1. Gain antena: gain antena merupakan karakteristik yang paling penting dan mencerminkan kemampuan antena untuk mengirimkan gelombang yang diinginkan ke arah yang dituju. Untuk antena parabola, efisiensinya tidak mencapai $100 \%$ karena beberapa daya hilang oleh spill over dan pabrikasi antena yang tidak sempurna. Secara komersial, efisiensi antena antara 50\%-70\% [8]. Besarnya gain antena dapat diperoleh dengan persamaan (1):

$G=20 \log f+20 \log d+10 \log \eta+20.4$

Keterangan:

$G=$ Gain Antena (dB)

$f=$ Frekuensi $(\mathrm{GHz})$

$d=$ Diameter antena $(\mathrm{m})$

$\eta=$ Efisiensi Antena $(\%)$

2. Free Space Loss (FSL): rugi-rugi propagasi di ruang bebas antara dua antena akibat energi yang tersebar atau dapat juga dikatakan power loss diantara transmitter dan receiver [9]. Besarnya kecilnya FSL dapat diperoleh dengan Persamaan (2).

$F S L=92.45+20 \log D+20 \log f$

Keterangan:

$D=\operatorname{Jarak}(\mathrm{km})$

$f=$ Frekuensi $(\mathrm{GHz})$

3. Emitted Isotropic Radiated Power (EIRP): daya maksimum sinyal gelombang mikro yang dipancarkan dari antenna pemancar untuk menujukan nilai efektif daya yang dipancarkan oleh antenna pemancar atau dikatakan daya yang diperkuat. EIRP dihitung dengan menjumlahkan daya keluaran antenna pemancar dengan gain antenna kemudian dikurangi loss [10]. Persamaan untuk EIRP sesuai dengan Persamaan (3)

$E I R P=P_{T X}+G_{\text {Antena }}-L_{T X}$

Keterangan:

$P_{T X}$ : Daya pancar $(\mathrm{dBm})$

$G_{\text {Antena }}:$ Gain antena $(\mathrm{dBi})$

$L_{T X}$ : Transmitter loss $(\mathrm{dB})$

4.Isotropic Received Level (IRL): tingkat daya isotropic yang diterima oleh stasiun penerima. Untuk mendapatkan nilai daya pada antenna penerima harus diperoleh nilai IRL lebih dahulu [11]. Persamaan untuk IRL sesuai dengan Persamaan (4)

$I R L=E I R P-F S L$

Keterangan:

$I R L=$ Isotropic Received Level $(\mathrm{dBm})$

$E I R P=$ Effective Isotropic Radiated Power $(\mathrm{dBm})$

$F S L=$ Free Space Loss $(\mathrm{dB})$

5. Received Signal Level (RSL): level daya yang diterima oleh perangkat pemroses (decoding). Nilai dari RSL dipengaruhi oleh rugi-rugi saluran pada sisi antenna penerima dan penguatan antenna penerima. Nilai RSL dihitung pada Persamaan (5) [12]

$R S L=I R L+G_{R X}-L_{R X}$

Keterangan:

$R S L=$ Received Signal Level $(\mathrm{dBm})$

$I R L=$ Isotropic Received Level $(\mathrm{dBm})$

$G_{R X}=$ Gain Antena $(\mathrm{dBi})$

6. Hoploss: perbedaan antara kelebihan dan kekurangan pada gelombang mikro. Jika gain adalah penguatan di kedua sisi, sedangkan loss adalah jumlah redaman ruang bebas dan atmosfer (uap air dan oksigen). Jumlah hoploss dinyatakan dalam Persamaan (6) [12]

$L_{h}=F S L+L_{T X}+L_{R x}+L_{A t m}-\left(G_{T X}+G_{R X}\right)$

Keterangan:

$L_{h} \quad=$ Hoploss $(\mathrm{dB})$

$F S L=$ Free Space Loss $(\mathrm{dB})$

$L_{T X}=$ Transmit Loss $(\mathrm{dB})$

$L_{R x}=$ Receive Loss $(\mathrm{dB})$

$L_{\text {Atm }}=$ Atmosphere Loss $(\mathrm{dB})$

$G_{T X}=$ Gain Antena Penerima $(\mathrm{dBi})$

$G_{R X}=$ Gain Antena Pengirim (dBi)

7. Availability: ukuran kehandalan sistem. Secara ideal, sebuah system yang baik harus memiliki nilai $100 \%$, tetapi hal tersebut tentu saja tidak seperti itu. Didalam suatu sistem pasti ada nilai ketidaktersediaan, misalnya karena fading, interferensi, dan lain sebagainya loss [10]. Adapun nilai availability dan unavailability dapat dilihat pada Persamaan (8) dan (9)

$A v_{\text {path }}=\left(1-U n A V_{\text {path }}\right) \times 100 \%$

$U n A V_{\text {path }}=a \times b \times 2.5 \times f \times D^{3} \times 10^{-6} \times 10^{-\frac{F M}{10}}$

Keterangan:

$F M=$ Fading Margin $(\mathrm{dB})$

$D \quad=$ Jarak $(\mathrm{km})$

$f \quad=$ Frekuensi $(\mathrm{GHz})$

$U n A V_{\text {path }}=$ Ketidakhandalan Sistem

$A v_{\text {path }} \quad=$ Kehandalan Sistem

8. Fading Margin disebut dengan cadangan daya. Digunakan untuk mempertahankan level sinyal terima di atas level ambang batas (threshold). Untuk mencari besarnya cadangan daya diperlukan beberapa parameter, antara lain kehandalan sistem, panjang lintasan yang ditempuh, faktor kekasaran bumi, faktor iklim dan frekuensi [13]:

$$
\begin{aligned}
& F M=30 \log D+10 \log (a \times b \times 2,5 f)- \\
& 10 \log \text { UnAvpath }
\end{aligned}
$$

Faktor kekasaran bumi dinotasikan dalam a dan $b$ adalah faktor iklim, keduanya diambil dari nilai yang berbeda untuk kondisi geografis dan iklim yang berbeda, adapun nilai a dan b adalah:

$\mathrm{a}=4$ untuk daerah halus, laut, danau, dan gurun 
Page $\mid 211_{D}$. Optimasi Jaringan Microwave Teknik Space

\section{Diversity}

Sistem ini hanya membutuhkan satu frekuensi kerja. Pada sistem ini pengirim dan penerima dilakukan dengan menggunakan dua antena yang dipasang sedemikian rupa sehingga antena satu dengan yang lainnya terletak pada bidang vertikal secara terpisah dengan jarak $100 \lambda, 125 \lambda, 150 \lambda, 175 \lambda$ dan $200 \lambda$ Konfigurasi space diversity ditunjukkan pada gambar 2.

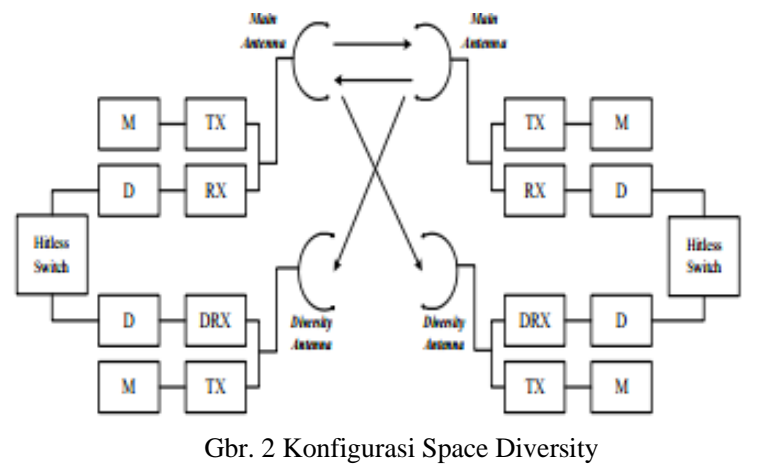

Untuk mendapatkan operasi yang optimal, maka penentuan jarak antara dua antena yang berurutan secara vertikal harus memenuhi nilai [14]:

$S=\frac{3 \times \lambda \times R}{D}$

Keterangan:

$s=$ jarak spasi antar antena $(\mathrm{m})$

$\lambda=$ panjang gelombang $(\mathrm{m})$

$R=$ jari-jari bumi $(6370 \mathrm{Km})$

$D=$ panjang lintasan $(\mathrm{Km})$

\section{PEMBAHASAN}

Sesuai dengan TABEL II, site yang digunakan adalah site Cipetir dan Cibadak. Site Cipetir terletak pada latitude $065202.38 \mathrm{~S}$, longitude $1064107.58 \mathrm{E}$ dan ketinggian $664.4 \mathrm{~m}$. Site Cibadak terletak pada latitude $065340.00 \mathrm{~S}$, longitude $1064706.38 \mathrm{E}$ dan ketinggian $388.2 \mathrm{~m}$.

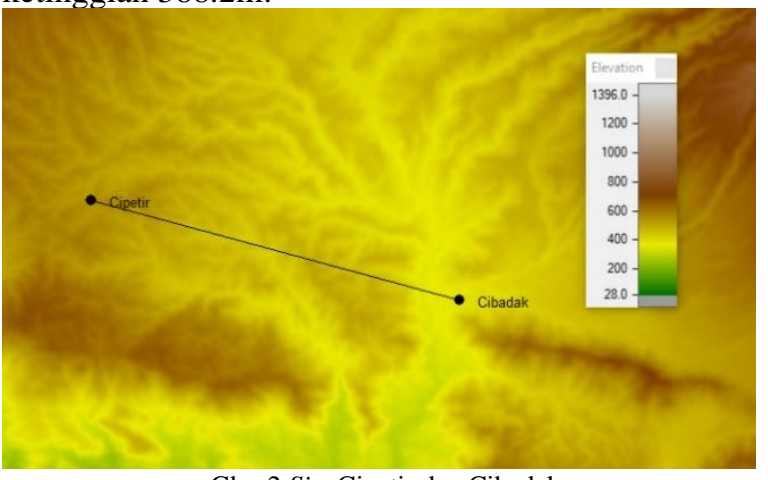

Gbr. 2 Site Cipetir dan Cibadak

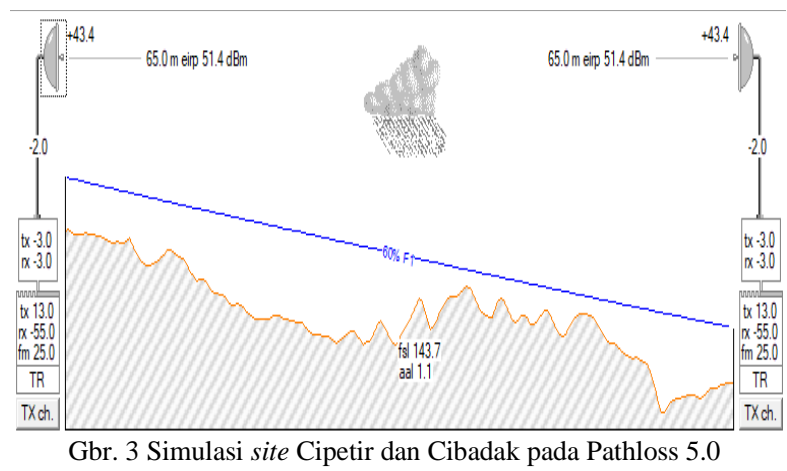

Dari simulasi di atas menghasilkan data keluaran seperti pada TABEL III.

TABEL III

AVAILABILITY PADA SITE CIPETIR DAN CIBADAK

\begin{tabular}{|l|c|}
\hline $\begin{array}{c}\text { Standar } \\
\text { Perhitungan }\end{array}$ & $\begin{array}{c}\text { Annual Rain + Multipath } \\
\text { Availability (\%) }\end{array}$ \\
\hline Vigants Barnett & 99.86112 \\
\hline ITU-R & 99.87924 \\
\hline
\end{tabular}

Berdasarkan TABEL III, hasil dari simulasi tanpa menggunakan space diversity, dengan menggunakan standar Vigants Barnett menghasilkan nilai Annual Rain + Multipath Availability $99.86112 \%$ dan dengan menggunakan standar ITU-R menghasilkan nilai Annual Rain + Multipath Availability $99.87924 \%$.

Nilai Annual Rain + Multipath Availability dengan menggunakan standar Vigants Barnett, menghasilkan $99.86112 \%$. Nilai ini jika dihitung dalam jangka waktu satu tahun sistem akan mengalami kegagalan selama 729.95328 menit atau 12.165888 jam atau 0.506912 hari.

Nilai Annual Rain + Multipath Availability dengan menggunakan standar ITU-R, menghasilkan 99.86112\%. Nilai ini jika dihitung dalam jangka waktu satu tahun sistem akan mengalami kegagalan selama 634.71456 menit atau 10.578576 jam atau 0.440774 hari.

Berdasarkan standar ITU-T G.821, nilai availability yang dihasilkan pada simulasi awal ini masih belum memenuhi standar, karena nilai availability sistem ini masih kurang dari $99.995 \%$. Untuk dapat meningkatkan nilai availability dari sistem ini maka simulasi selanjutnya dilakukan optimasi dengan menggunakan space diversity. 


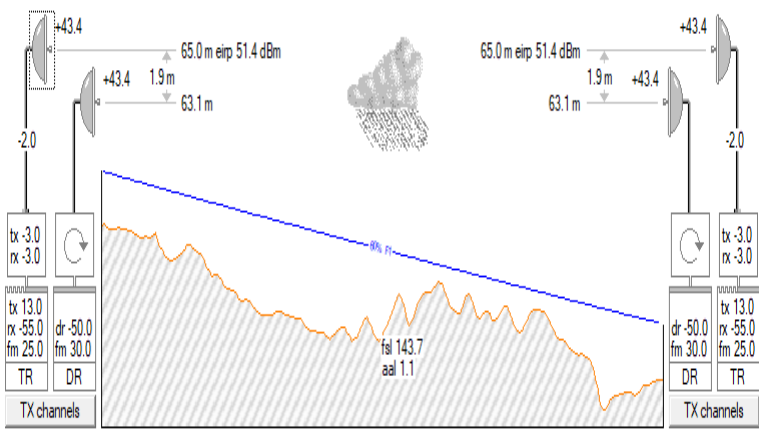

Gbr. 4 Simulasi site Cipetir dan Cibadak pada Pathloss 5.0 dengan space diversity

Pada simulasi link microwave dengan menggunakan space diversity, kita perlu menentukan jarak tinggi antena space diversity. Jarak yang digunakan pada penelitian ini adalah $100 \lambda, 125 \lambda, 150 \lambda, 175 \lambda$ dan $200 \lambda$.

TABEL IV

AVAILABILITY PADA SITE CIPETIR DAN CIBADAK DENGAN MENGGUNAKAN SPACE DIVERSITY

\begin{tabular}{|l|c|c|}
\hline \multirow{2}{*}{$\begin{array}{c}\text { Jarak } \\
\text { Diversity }\end{array}$} & \multicolumn{2}{|c|}{$\begin{array}{c}\text { Annual Rain + Multipath } \\
\text { Availability (\%) }\end{array}$} \\
\cline { 2 - 3 } Tanpa Diversity & 99.86112 & 99.87924 \\
\hline $100 \lambda$ & 99.90607 & 99.9118 \\
\hline $125 \lambda$ & 99.90789 & 99.9118 \\
\hline $150 \lambda$ & 99.90911 & 99.9118 \\
\hline $175 \lambda$ & 99.90981 & 99.9118 \\
\hline $200 \lambda$ & 99.91027 & 99.9118 \\
\hline
\end{tabular}

Dengan menggunakan standar perhitungan Vigen barnet, simulasi antara site Cibadak dan Cipetir sebelum menggunakan space diversity menghasilkan nilai Annual Rain + Multipath Availability $99.86112 \%$. Setelah menggunakan space diversity, simulasi antara site Cibadak dan Cipetir menghasilkan nilai Annual Rain + Multipath Availability $99.91027 \%$ pada jarak antena space diversity 200入. Jika dihitung dalam jangka waktu satu tahun sistem akan mengalami kegagalan selama 471.62088 menit atau 7.860348 jam atau 0.3275145 hari.

Dengan menggunakan standar perhitungan ITU-R, simulasi antara site Cibadak dan Cipetir sebelum menggunakan space diversity menghasilkan nilai Annual Rain + Multipath Availability 99.87924\%. Setelah menggunakan space diversity, simulasi antara site Cibadak dan Cipetir menghasilkan nilai Annual Rain + Multipath Availability $99.9118 \%$ pada jarak antena space diversity 200入. Jika dihitung dalam jangka waktu satu tahun sistem akan mengalami kegagalan selama 463.5792 menit atau 7.72632 jam atau 0.32193 hari.

Dengan menggunakan standar perhitungan Vigen barnet, penggunaan space diversity meningkatkan nilai availability sebesar $0.04915 \%$. Dengan menggunakan standar perhitungan ITU-R, penggunaan space diversity meningkatkan nilai availability sebesar $0.03256 \%$.

Dengan menggunakan space diversity, link microwave site Cipetir dan Cibadak, sudah mengalami peningkatan nilai availability namun peningkatan nilai availability dengan menggunakan space diversity pada link ini masih belum memenuhi standar dari ITU-T G.821 karena nilai availability masih kurang dari $99.995 \%$

\section{PENUTUP}

Pada penelitian ini dilakukan simulasi link microwave antara site Cibadak Cipetir yang dioptimasi dengan menggunakan space diversity. Dengan menggunakan standar perhitungan Vigen barnet, penggunaan space diversity meningkatkan nilai availability sebesar $0.04915 \%$. Dengan menggunakan standar perhitungan ITU-R, penggunaan space diversity meningkatkan nilai availability sebesar $0.03256 \%$. Dengan menggunakan space diversity nilai availability sudah meningkat walaupun masih belum memenuhi standar ITU-T G.821.

\section{UCAPAN TERIMA KASIH}

Terima kasih disampaikan kepada Deputi Bidang Penguatan Riset Dan Pengembangan, Kementerian Riset Dan Teknologi / Badan Riset Dan Inovasi Nasional yang telah memberikan bantuan dana penelitian ini melalui PDP. Terima kasih juga kami sampaikan kepada LPPM IT Telkom Purwokerto yang memfasilitasi penelitian ini.

\section{REFERENSI}

[1] A. Wahyudin And A. Hikmaturokhman, "Analisis Perbandingan Passive Repeater Back-To-Back Antenna Dan Passive Repeater Plane Reflector Menggunakan Pathloss 5 . 0 Analisis Perbandingan Passive Repeater Back-To-Back Antenna Dan Passive Repeater Plane Reflector Passive Repeater Antenna And Plane," No. October, Pp. 0-8, 2017.

[2] W. Alfiyani, E. S. Nugraha, And Y. Rahmawati, "Perancangan Rekonfigurasi Link Transmisi Microwave Long Haul Iv Nagari - Kamang Baru Dengan Space," J. Telecommun. Electron. Control Eng., Vol. 8275, Pp. 1-8, 2019.

[3] O. I. Zuherry, "Perancangan Jaringan Transmisi Microwave Menggunakan Passive Repeater Back To Back Dan Double Flat Reflector Menggunakan Pathloss 5.0," J. Telecommun. Electron. Control Eng., Vol. 1, No. 01, Pp. 53-62, 2019

[4] Z. H. Pradana And A. Wahyudin, "Analisis Optimasi Space Diversity Pada Link Microwave Menggunakan Itu Models Analysis Of Space Diversity Optimization On Microwave Links Using Itu Models," Pp. 586-592, 2017.

[5] S. H. Triwibowo, E. Wahyudi, And S. Larasati, "Perbandingan Penggunaan Teknik Diversity Pada Jaringan Gelombang Mikro Di Lingkungan Danau," J. Nas. Tek. Elektro Dan Teknol. Inf., Vol. 8, No. 3, P. 290, 2019.

[6] D. B. Liu, E. Wahyudi, And E. S. Nugraha, "Pengaruh Space Diversity Terhadap Peningkatan Availability Pada Jaringan Microwave Lintas Laut Dan Lintas Pegunungan," J. Elektro Dan Telekomun. Terap., Vol. 4, No. 2, P. 541, 2017.

[7] Y. Y. Rahmawati And A. Wahyudin, "Perancangan Jaringan Backhaul Sistem Transmisi Gelombang Mikro Digital 
Menggunakan Frequency Diversity Dan Tanpa Diversity Di Wilayah Kepulauan Riau," Techno (Jurnal Fak. Tek. Univ. Muhammadiyah Purwokerto), Vol. 19, No. 2, P. 63, 2018

[8] A. Hikmaturrokhman, E. Wahyudi, And H. Sulaiman, "Analisa Pengaruh Interferensi Terhadap Availability Pada Jaringan Transmisi Microwave," Ecotipe, Vol. 1, No. 2, Pp. 11-12, 2014.

Page | 213 [9] R. G. Winch, Telecommuniction Transmission Sytem, Vol. 66. New York, 2012

[10] A. Hikmaturokhman And A. Wahyudin, Perancangan Jaringan Gelombang Mikro Menggunakan Pathloss 5 Teori Dan Simulasi. Yogyakarta: Pustaka Ilmu, 2018.

[11] R. L. Freeman, Radio System Design For Telecommunications. New York: John Wiley \& Sons, 2006.

[12] G. Kizer, Digital Microwave Communication: Engineering Point-To-Point Microwave Systems. Amerika, 1945.

[13] A. Hikmaturokhman, A. Wahyudin, W. E. Rinanda, S. Pramono, A. Hidayat, And A. Sarah, "Analysis Of Microwave Network Design Using Back-To-Back Passive Repeaters With The Influence Of Interference Based On Itu-T-G821 Standard,' J. Commun., Vol. 15, No. 4, Pp. 318-324, 2020.

[14] M. A. Kurnia, E. Wahyudi, And S. Larasati, "Perbandingan Perfomansi Hybrid Diversity Dan Space," vol. 5, no. 2, pp. 285-292, 2020. 